Revista de
Economild
Contemporâned

\title{
HETEROGENEIDADE ESTRUTURAL: UMA ANÁLISE SEGUNDO PORTE, SETOR E IDADE DAS EMPRESAS INDUSTRIAIS BRASILEIRAS (2007-2016) ${ }^{1}$
}

\author{
Marisa dos Reis A. Botelho ${ }^{a}$ \\ Juliene Barbosa Ferreira ${ }^{b}$ \\ Graciele de Fátima Sousa ${ }^{c}$ \\ Michelle de Castro Carrijo ${ }^{d}$ \\ Ariana Cericatto da Silva ${ }^{e}$
}

\begin{abstract}
${ }^{\text {a }}$ Professora Titular do Instituto de Economia e Relações Internacionais (IERI) da Universidade Federal de Uberlândia (UFU) e pesquisadora do Conselho Nacional de Desenvolvimento Científico e Tecnológico (CNPq). Uberlândia, MG, Brasil. ORCID: https://orcid.org/0000-0003-4905-6673.

${ }^{\text {b }}$ Professora da Universidade Federal do Triângulo Mineiro (UFTM). Uberaba, MG, Brasil. ORCID: https://orcid.org/0000-0002-5637-2212.
\end{abstract}

${ }^{\mathrm{c}}$ Economista do Centro de Estudos, Pesquisas e Projeto Econômico-Sociais (CEPES) do IERI/UFU. Uberlândia, MG, Brasil. ORCID: https://orcid.org/0000-0002-5027-8188.

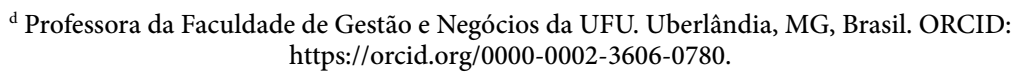

e Doutoranda no Programa de Pós-Graduação em Economia (PPGE) da UFU. Uberlândia, MG, Brasil. ORCID: https://orcid.org/0000-0002-4737-3600.

\section{Recebido em 26 fevereiro 2020}

Aceito em 03 março 2021

RESUMO: Este artigo discute a heterogeneidade estrutural da indústria brasileira a partir da análise estatística de um conjunto de dados que a evidenciam de acordo com o porte, setor e idade das empresas na indústria de transformação brasileira no período de 2007 a 2016. Foi realizada uma análise descritiva dos dados, que foram obtidos em tabulação especial da Pesquisa Industrial Anual Empresa (PIA/Empresa) e do Cadastro Central de Empresas (CEMPRE), do Instituto Brasileiro de Geografia e Estatística (IBGE). Os resultados encontrados permitem mostrar que a heterogeneidade

Correspondência para: Marisa dos Reis A. Botelho

Contato: botelhomr@ufu.br

1 As autoras agradecem o apoio financeiro da Fundação de Apoio à Pesquisa de Minas Gerais (Fapemig) à elaboração deste trabalho, por meio do projeto Demanda Universal (APQ 02761-15). 
estrutural extrapola a conhecida relação com o porte. Verificou-se que a heterogeneidade é bastante significativa também intraporte, segundo idade e setor de atividade. Ao abordar a questão de porte e longevidade, entende-se que este trabalho contribui para a discussão da situação da indústria frente ao processo de desindustrialização em curso na economia brasileira.

PALAVRAS-CHAVE: indústria brasileira; heterogeneidade estrutural; porte das empresas; idade das empresas.

CLASSIFICAÇÃO JEL: L16; L25; L60. 


\title{
STRUCTURAL HETEROGENEITY: AN ANALYSIS ACCORDING TO SIZE, SECTOR AND AGE OF BRAZILIAN INDUSTRIAL COMPANIES (2007-2016)
}

\begin{abstract}
Several recent studies show that structural heterogeneity is an important feature of the Brazilian manufacturing sector. This paper carries out a statistical analysis of heterogeneity examining the Brazilian manufacturing structure in terms of firm size, age, and sector of activity, from 2007 to 2016. Our descriptive analysis used datasets extracted from Pesquisa Industrial Anual Empresa (PIA/Empresa) and Cadastro Central de Empresas (CEMPRE), both collected by the IBGE, the Brazilian official statistics bureau. The analysis of the labor productivity indicator shows that structural heterogeneity goes beyond firm size, being likewise significant in terms of firm's age and sector of activity. In addressing the issues of firm size and longevity, our work contributes to discussing the situation of domestic manufacturing sectors in the ongoing deindustrialization of the Brazilian economy.
\end{abstract}

KEYWORDS: Brazilian manufacturing sector; productive heterogeneity; firm size; firm age. 


\section{INTRODUÇÃO}

O tema da heterogeneidade estrutural passa a fazer parte de forma mais intensa dos debates acadêmicos a partir dos anos de 1950, após a Segunda Guerra Mundial. Muitos autores, como Pinto (1970), Prebisch (1950), Lewis (1954) e Solow (1956), desenvolveram trabalhos seminais buscando compreender as diferenças estruturais dentro das economias. Na América Latina e Caribe, foi com a criação da Comissão Econômica para América Latina e Caribe (CEPAL) que essa discussão ganhou importância. Baseada em uma perspectiva estruturalista, essa escola do pensamento defendia que as economias latinoamericanas absorveram o progresso tecnológico de forma assimétrica e heterogênea, o que teria elevado as diferenças de produtividade e, consequentemente, originado as profundas desigualdades na composição industrial.

Esse tema também tem sido recorrentemente tratado para a economia brasileira desde o pós-guerra, quando esteve na raiz das discussões políticas que levaram à implementação de planos de desenvolvimento focados em mudanças quantitativas e qualitativas no processo de industrialização, em especial nas décadas de 1960 e 1970 . Esses planos, com resultados bastante positivos, foram interrompidos com a crise do Balanço de Pagamentos na década de 1980 e, posteriormente, com a abertura econômica dos anos 1990.

Desde então, avança a desindustrialização da economia brasileira que, de acordo com diversos trabalhos recentes, foi classificada como precoce frente às características desse processo em países desenvolvidos (PALMA, 2005; BRESSER-PEREIRA, 2008; CANO, 2012; NASSIF; FEIJÓ; ARAUJO, 2015). Com o avanço da perda de participação da indústria no produto interno bruto (PIB), a tendência à convergência nos níveis de produtividade, verificada por Rodríguez (1998) para as décadas de 1960 e 1970, é revertida e, especialmente pós anos 1990, volta a ampliar-se.

Os diferenciais de produtividade como medida da heterogeneidade estrutural da indústria brasileira foram identificados, entre outros, por Kupfer e Rocha (2005), Catela e Porcile (2013a; 2013b), Squeff e Nogueira (2015) e Catela (2018). Há diversas razões arroladas para explicar a queda da produtividade, de ordem macro e microeconômicas, ou decorrentes de fatores externos. Do ponto de vista microeconômico, esses diferenciais são relacionados, em geral, às questões ligadas à composição setorial das atividades industriais e ao porte das empresas.

Em relação aos setores de atividade, as dificuldades do ambiente econômico foram mais intensas para os setores intensivos em tecnologia. Em um ambiente de mudanças estruturais nos países centrais, os países periféricos, salvo raras exceções, não acompanharam as tecnologias da $3^{\text {a }}$ Revolução Industrial e, tampouco, os avanços da 
$4^{\mathrm{a}}$ Revolução, comumente denominada "Indústria 4.0". No caso da economia brasileira, essa situação se explicita no grande e crescente déficit comercial da indústria de transformação desde o início dos anos 2000 e uma situação de especialização regressiva no comércio internacional (NASSIF; CASTILHO, 2020).

Em relação ao porte, os efeitos da instabilidade econômica tendem a produzir efeitos maiores para as empresas de pequeno porte, dadas as suas debilidades estruturais frente às grandes empresas (STEINDL, 1990) e as maiores dificuldades de acesso a recursos bancários (OECD, 2006). Com vistas a contornar parte dessas dificuldades, foram implementados diversos instrumentos de apoio às pequenas empresas no âmbito dos planos de política industrial dos anos 2000 (MATOS; ARROIO, 2011).

À luz dessas considerações gerais, este trabalho busca contribuir para a discussão da heterogeneidade estrutural da indústria brasileira ao sistematizar um amplo conjunto de dados inéditos, que evidenciam sua manifestação com relação ao porte, setor e idade das empresas na indústria de transformação brasileira para o período de 2007 a 2016. Os objetivos específicos são: i) apresentar as diferenças de produtividade ao longo do tempo por porte e por idade; ii) apresentar as diferenças setoriais de produtividade por porte e por idade em dois pontos do tempo, quais sejam, 2007 e 2016. O período em análise, de dez anos, foi escolhido em virtude de permitir utilizar os dados mais atualizados disponíveis na série da PIA e elaborados com a CNAE 2.0. Ademais, esse é o período em que mudanças importantes aconteceram na economia brasileira, em especial a volta dos planos de política industrial, o que permite traçar um quadro, ainda que em caráter exploratório, dos seus efeitos na estrutura produtiva.

Para cumprir esses objetivos, foram levantados para análise, a partir de uma tabulação especial, dados secundários da Pesquisa Industrial Anual - Empresa (PIA/Empresa) e do Cadastro Central de Empresas (CEMPRE), ambas desenvolvidas pelo Instituto Brasileiro de Geografia e Estatística (IBGE). A principal variável investigada foi a produtividade do trabalho, medida pela relação do valor da transformação industrial (VTI) pelo pessoal ocupado (PO).

Além dessa introdução e das considerações finais, o trabalho foi estruturado em mais três seções. A primeira seção traz o referencial analítico, na qual se resgata a discussão de heterogeneidade estrutural a partir da contribuição do CEPAL e se destacam os trabalhos recentes que consideram as diferenças de produtividade segundo o porte. A segunda seção apresenta a metodologia utilizada para o desenvolvimento do trabalho, enquanto a terceira seção dedica-se à análise dos resultados encontrados. 


\section{REFERENCIAL ANALÍTICO}

A discussão sobre heterogeneidade estrutural na América Latina se originou, em especial, dos trabalhos iniciais de Raúl Prebisch, os quais buscavam compreender a forma particular com que as economias latino-americanas se desenvolviam, a partir do incremento tecnológico de forma desigual. O tema se difundiu em âmbito internacional no período pós-guerra, quando as economias envolvidas no conflito começaram seus processos de reconstrução, buscando reduzir o hiato econômico existente entre os países desenvolvidos e os subdesenvolvidos.

No âmbito do mainstream economics, Lewis (1954) também apontava a dualidade estrutural, ou seja, identificava a existência de heterogeneidade nas estruturas produtivas, a qual estava alicerçada na presença conjunta de dois tipos de estruturas, uma moderna e outra atrasada. Na América Latina e no Caribe, desde a criação da Comissão Econômica para América Latina e Caribe (CEPAL), esse tema mereceu forte atenção. Sua perspectiva crítica ao subdesenvolvimento, acabou por torná-la uma escola do pensamento preocupada em compreender o modelo de mudanças estruturais ocorridas ao longo do tempo na América Latina e Caribe, uma vez que a modernização desses países ocorreu de forma heterogênea, reforçando, assim, as desigualdades regionais e intrarregionais.

A análise da heterogeneidade estrutural aqui apresentada, parte do embasamento teórico proposto por Pinto (1970), cuja premissa é de que existem três estruturas principais que se manifestam de forma mais pungente, sendo: i) uma estrutura "primitiva", a qual apresenta níveis de produtividade do trabalho mais baixos, que se assemelham àqueles encontrados na economia no período colonial; ii) no outro extremo, apresenta uma estrutura "moderna", que possui níveis de produtividade próximos à média das economias de países desenvolvidos e, por fim, iii) uma estrutura “intermediária”, que se caracteriza justamente por se encaixar entre as duas anteriores. Embora com mudanças ao longo do tempo, entende-se que essa tipologia continua representativa da economia dos países latino-americanos e, em particular, do Brasil.

A partir dessa perspectiva, define-se que a heterogeneidade estrutural ocorre quando se observa diferenças de produtividade do trabalho entre as estruturas primitiva, moderna e intermediária, cuja descontinuidade estrutural é marcante entre os setores produtivos, de forma que não se observa uma tendência à homogeneização (ou seja, a camada moderna não consegue "arrastar" a produtividade dos setores atrasados) e a representatividade do setor atrasado é particularmente notável, principalmente se comparado às economias desenvolvidas (CEPAL, 2010; INFANTE, 2011; PINTO, 1970). Segundo Pinto (1970), a persistência de setores produtivos com diferentes níveis de produtividade do trabalho tende a reproduzir a separação entre um setor dinâmico, 
estruturado ou formal, e um setor tradicional, não estruturado ou informal, que ficam excluídos de um cenário de desenvolvimento econômico e progresso social.

A perspectiva do CEPAL de análise da heterogeneidade estrutural continua orientando trabalhos recentes sobre esse tema, direta ou indiretamente. Araújo e Costa (2012) e Nogueira (2017), entre outros, entendem que uma economia desenvolve e homogeneíza sua estrutura produtiva no longo prazo ao transferir mão de obra dos setores de baixa produtividade para os setores de alta produtividade. Nesse sentido, a produtividade do trabalho pode aumentar por duas razões, quais sejam, pelo deslocamento de fatores produtivos dos setores atrasados para os setores modernos da economia e pelo aumento intrínseco da produtividade de cada setor que é gerado pelas mudanças tecnológicas que ocorrem ao longo do desenvolvimento de cada país.

O desenvolvimento tecnológico insuficiente não permite que o progresso técnico de alguns setores produza efeitos de transbordamentos (spillovers) de forma homogênea para todos os demais setores da economia de determinado país. De acordo com Infante (2011) e Gusso, Nogueira e Vasconcelos (2011), a presença de heterogeneidade estrutural remete aos desdobramentos e à persistência das profundas desigualdades econômicas e sociais que se observam nos países em desenvolvimento. Além disso, a persistência da heterogeneidade estrutural coloca dificuldades para o estabelecimento de um processo de desenvolvimento inclusivo ou um modelo de crescimento com convergência de produtividade entre os setores, em linha com as proposições pioneiras da CEPAL.

Logo, a heterogeneidade estrutural é fruto das insuficientes possibilidades de gerar e difundir o progresso técnico devido às características da especialização produtiva. Assim, aqueles países que não captam esses novos paradigmas tecnológicos apresentarão persistência de heterogeneidade estrutural, baixos salários e um crescimento restringido pelo balanço de pagamentos (RODRÍGUEZ, 1998; CIMOLI, 2005; INFANTE, 2011).

O tema da heterogeneidade produtiva ganhou contribuições importantes nas últimas décadas com a difusão da literatura neoschumpeteriana/evolucionária (NELSON; WINTER, 1982; DOSI; NELSON, 2018). Entre outras, as contribuições pioneiras de Pavitt (1984), para a discussão das diferenças setoriais, e as de Teece e Pisano (1994) e Nelson (1991), para investigar as diferenças em rotinas e estratégias empresariais, estimularam uma fértil discussão acadêmica que realça a questão da diversidade, nos âmbitos setorial e intrassetorial (DOSI; LECHEVALIER; SECCHI, 2010). Em consonância com o pensamento do CEPAL, as diferenças na geração e incorporação do progresso técnico em nível de países, setores e empresas é essencial para explicar a heterogeneidade produtiva na abordagem neoschumpeteriana. Essas diferenças estão fortemente relacionadas com os setores de atividade e tamanho das empresas e têm sido bastante exploradas pelos trabalhos mais recentes da CEPAL (CIMOLI, 2005; INFANTE, 2011; CORREA; LEIVA; STUMPO, 2018). 
Em relação à idade, um dos focos desse artigo, um conjunto de trabalhos recentes tem se dedicado à essa discussão, a partir do entendimento de que os efeitos do tamanho sobre a performance das firmas têm sido muito mais estudados que os da idade (COAD et al., 2018). Conforme mostram vários estudos sistematizados por Coad (2018), as diferenças nas taxas de crescimento e nos níveis de produtividade não são uniformes ao longo do tempo de existência das empresas. Em uma perspectiva evolucionária, as taxas de natalidade, crescimento e mortalidade apresentam importantes diferenças ao longo do ciclo de vida das empresas, com evidências empíricas de que as taxas de mortalidade são mais elevadas nos primeiros anos de existência, mas são as empresas mais jovens que apresentam as mais altas taxas de crescimento. Essas relações sofrem influência de vários fatores, entre eles, as atividades de pesquisa e desenvolvimento (CEFIS; MARSILI, 2006) e a inserção no comércio internacional (GRAZZI; MOSCHELLA, 2018).

\subsection{A HETEROGENEIDADE ESTRUTURAL NA ECONOMIA BRASILEIRA}

Em consonância com as discussões pioneiras da CEPAL, a discussão sobre a heterogeneidade estrutural da economia brasileira, conforme tratada por Furtado (1986) e sumarizada em Rodríguez (1998), segue sendo um importante tema de pesquisa, com vários trabalhos voltados à essa temática, desenvolvidos no período recente.

Catela, Cimoli e Porcile (2015) buscaram discutir se a hipótese da heterogeneidade estrutural se aplica ao caso do setor industrial brasileiro. Os autores concluíram que a distribuição da produtividade não se alterou significativamente ao longo do período de 2000 a 2008, o que houve foi uma tendência de concentração. Segundo esses autores, as forças que sustentam a heterogeneidade estrutural são aquelas identificadas pela literatura schumpeteriana como os motores da polarização, dando origem a retornos crescentes e dependência de trajetória que concentram a inovação e a aprendizagem nas empresas que avançam. Os dados também apontaram diferenças significativas nos níveis de produtividade e no crescimento da produtividade em setores com diferentes intensidades tecnológicas.

Em outro trabalho semelhante, Catela e Porcile (2013a) analisaram a distribuição das firmas entre diferentes estratos de produtividade dentro da indústria de transformação no período de 2000 a 2009, assim como a dinâmica de transição destas firmas dentro e entre estes estratos. Além disso, buscaram testar se a heterogeneidade produtiva é um fenômeno persistente no tempo. Em suas conclusões, os autores confirmaram a elevada e persistente heterogeneidade dentro da indústria 
de transformação brasileira. Os resultados ratificaram a existência de forte heterogeneidade intersetorial e intrassetorial.

Ainda com referência ao caso brasileiro, Catela e Porcile (2013b) investigaram a dinâmica da produtividade do trabalho das diferentes divisões da indústria de transformação brasileira e os seus determinantes. Os autores verificaram que a produtividade da indústria permaneceu praticamente inalterada entre 2000 e 2008, o que significou queda no adensamento das cadeias produtivas brasileiras, implicando deterioração da balança comercial, dado que as importações de insumos e bens intermediários aumentaram. Além disso, a dinâmica da distribuição condicional de produtividade evidencia a persistência da dispersão entre as divisões na indústria, o que confirma a ampla heterogeneidade que persiste ao longo do período.

De Negri e Cavalcante (2014) sumarizam diversos estudos sobre a evolução da produtividade da economia brasileira nos anos 2000. Para os autores, qualquer que seja a métrica utilizada (produtividade total dos fatores ou produtividade do trabalho) e a metodologia de análise, há uma convergência nos resultados que mostram a fraca evolução da produtividade desde o final dos anos 1970 e, mais especificamente, desde o início dos anos 2000. Se observa um deslocamento entre o crescimento do PIB e da produtividade, dado que a economia brasileira apresentou altas taxas de crescimento do produto entre 2003 e 2010 . Com um crescimento muito baixo e aquém do verificado para países desenvolvidos e em desenvolvimento (caso dos países do BRICS - Brasil, Rússia, Índia, China e África do Sul), assinala-se o caráter estrutural da baixa produtividade da economia brasileira.

Em trabalho recente, Torezani (2020), a partir do método da decomposição da produtividade segundo setores de atividade para o período 1996-2016, também identifica a permanência da heterogeneidade estrutural na indústria brasileira. Para o autor, "o deslocamento do fator trabalho ocorreu tanto em direção às atividades menos produtivas quanto para atividades com menor crescimento da produtividade, resultando em uma mudança estrutural do tipo negativa, redutora da produtividade agregada da indústria” (p. 30).

A questão da heterogeneidade estrutural relacionada ao porte das empresas é, direta ou indiretamente, tratada em vários estudos sobre o tema. Destacam-se, na sequência, aqueles trabalhos que trataram mais diretamente a heterogeneidade segundo o porte, como os de Souza e Mazzali (2008), Hidalgo e Mata (2008) e Kupfer e Rocha (2005).

Souza e Mazzali (2008) buscaram reunir, a partir de uma amostra de pequenas empresas, um conjunto de elementos que permitisse mostrar que esse segmento é, em seu interior, heterogêneo, seja pelo número de empregados, pelos produtos e processos e/ou pelas formas de sua inserção em diferentes mercados. Os autores procuraram evidenciar a heterogeneidade do segmento das pequenas empresas, tanto 
no tamanho relativo das empresas, quanto nas formas de inserção. Para eles, heterogeneidade nas formas de inserção significa diferentes necessidades no que tange à continuidade das pequenas empresas no mercado e diferenças na sua possível contribuição, seja pela absorção da mão de obra, seja para contribuir na competitividade do setor em que se inserem.

Estes autores chegaram a quatro diferentes trajetórias de inserção para o segmento dos pequenos negócios: disputa de espaço em mercados ainda pouco oligopolizados e com acentuada concorrência em preços; identificação e exploração de oportunidades em "nichos" de mercado; parte integrante de aglomerações setoriais de empresas, sem liderança explícita; e inserção em redes de relações, mais frequentemente de subcontratação, comandadas por grandes empresas. Dessa forma, fica evidente que é inadequado o tratamento das pequenas empresas como um bloco homogêneo.

O trabalho de Hidalgo e Mata (2008) buscou mostrar as diferenças de produtividade para as firmas exportadoras e não exportadoras da indústria de transformação no período entre 1997 e 2003. Com o intuito de analisar a produtividade das firmas na indústria de transformação brasileira, os autores compararam a função de distribuição cumulativa da produtividade total dos fatores e da produtividade do trabalho para quatro grupos diferentes de firmas: exportadoras, não exportadoras, exportadoras entrando no mercado internacional e exportadoras saindo do mercado internacional. Encontraram maiores níveis de produtividade para as firmas exportadoras do que para as firmas não exportadoras. Em relação ao porte das empresas exportadoras, verificou-se que o grupo das firmas de pequeno porte possuíam maior nível de produtividade do que as não exportadoras.

Kupfer e Rocha (2005) também analisaram a evolução da produtividade da indústria brasileira e procuraram medir a heterogeneidade a partir da dispersão dos níveis de produtividade entre os distintos setores e dentro de cada setor, assim como suas causas. Os autores concluíram que a intensificação da heterogeneidade não é um fenômeno apenas intersetorial, mas que há também um forte componente intrassetorial, que está associado, pelo menos em parte, ao tamanho das empresas. O tamanho das empresas explica melhor a evolução da produtividade que o setor de atividade.

Segundo os autores, não houve, no Brasil, uma mudança estrutural intersetorial relevante ao longo dos últimos anos, mas sim uma significativa mudança estrutural intrassetorial. Isso aconteceu durante um processo de transformação em que as empresas de maior produtividade foram as que mais evoluíram, enquanto as restantes, geralmente de pequeno porte, encontraram maiores dificuldades para avançar.

A persistência dos diferenciais de produtividade entre grandes e pequenas empresas também foi identificado por Catela (2018). A autora utilizou o indicador de 
produtividade relativa interna ${ }^{2}$ para investigar a evolução dos diferenciais de produtividade segundo o porte das empresas para a indústria de transformação brasileira no período 2000-2014, em que vigoraram condições econômicas mais favoráveis que as da década de 1990, considerada no trabalho de Kupfer e Rocha (2005). Embora tenha havido uma pequena diminuição entre os diferenciais de produtividade das micro e pequenas empresas em relação às grandes no período mais recente, essa diminuição não se sustentou ao longo do tempo, dado que, após 2013, os diferenciais voltaram a subir.

Em suma, as assimetrias entre empresas de maior e menor tamanho indicam que o comportamento da indústria brasileira tem se caracterizado por um marcado aumento da heterogeneidade estrutural, principalmente de caráter intrassetorial. Nenhum desses estudos discutiu os efeitos da idade das empresas sobre os níveis de produtividade, tal como proposto no presente artigo.

\section{METODOLOGIA}

Para o desenvolvimento desse trabalho, foram utilizados dados secundários obtidos da Pesquisa Industrial Anual Empresa (PIA/Empresa) e do Cadastro Central de Empresas (CEMPRE), por meio de uma tabulação especial.

A PIA/Empresa é realizada pelo IBGE e possui em sua amostra todas as empresas industriais com 30 ou mais pessoas ocupadas. As demais empresas, numericamente majoritárias e com reduzida participação no total da atividade econômica, são objeto de seleção amostral. É importante destacar que essa pesquisa não inclui o setor informal, uma vez que fazem parte da PIA apenas aquelas empresas que possuem registro no Cadastro Nacional de Pessoa Jurídica (CNPJ) (IBGE, 2019a). O CEMPRE também é organizado pelo IBGE e consiste em um acervo de dados sobre o universo das empresas, reunindo informações provenientes de diversas pesquisas do IBGE e registros administrativos da Secretaria de Trabalho do Ministério da Economia como a Relação Anual de Informações Sociais (RAIS) (IBGE, 2019b).

Nessa tabulação especial, os dados são apresentados por faixa de idade, por porte da empresa e por setor de atividade da indústria de transformação, segundo a Classificação

\footnotetext{
A produtividade relativa interna é obtida pelo quociente entre o valor da produtividade do trabalho de cada segmento das micro, pequenas e médias empresas e o valor da produtividade do trabalho das grandes empresas em um país ou região (CORREA; LEIVA; STUMPO, 2018). Esse indicador também será usado no presente trabalho.
} 
Nacional de Atividades Econômicas a dois dígitos (CNAE 2.0), para o período de 2007 a 2016, no Brasil.

No presente trabalho, considera-se que as micro e pequenas empresas são estabelecimentos com até 99 pessoas ocupadas, as empresas de médio porte têm de 100 a 499 pessoas ocupadas e as grandes empresas empregam mais de 500 pessoas, seguindo a classificação adotada pelo Serviço Brasileiro de Apoio às Micro e Pequenas Empresas (SEBRAE, 2012). Já as faixas de idade das empresas foram assim definidas: firmas com menos de 10 anos, com 10 a 19 anos, entre 20 e 29 anos e aquelas com mais de 30 anos.

Considerando os apontamentos da seção anterior e as informações obtidas, a principal variável investigada no trabalho é a produtividade do trabalho, dada pela relação do Valor da Transformação Industrial (VTI) e pelo pessoal ocupado total (PO). ${ }^{3}$ Ressalta-se que os dados monetários foram atualizados para valores de 2016, utilizando o Índice Nacional de Preços ao Consumidor (INPC), elaborado e disponibilizado pelo IBGE. ${ }^{4}$

A metodologia adotada foi uma análise descritiva dos dados, investigando a manifestação de heterogeneidade estrutural na indústria de transformação do Brasil, considerando o porte, o setor e a idade das empresas. Além disso, utilizou-se o método diferencial-estrutural para a decomposição do crescimento da produtividade do trabalho. Para isso, calculou-se, com base nos trabalhos de Kupfer e Rocha (2005), Rocha, Tatsch e Cário (2019) e Torezani (2020), a participação dos distintos setores, termo $S_{i}$, no PO da indústria de transformação, em que o subscrito $i$ representa cada setor. Assim:

$$
S^{i}=\frac{P O_{i}}{P O}
$$

Em seguida, por meio do quociente entre VTI e PO, calculou-se o nível de produtividade do trabalho, $P_{i}$, também de cada setor $i$ da economia. O nível de produtividade foi calculado com base no quociente entre produtividade setorial e produtividade total. $\mathrm{O}$ sobrescrito 0 refere-se ao período inicial e o subscrito $T$ ao final,

3 Os indicadores comumente utilizados para medir a eficiência produtiva em nível de empresas são a produtividade do trabalho e a produtividade total dos fatores. Ambos são sujeitos à problemas de imprecisão de medidas. O indicador de produtividade do trabalho é, em geral, criticado por sua imprecisão e volatilidade, dado que não considera as horas trabalhadas e é muito afetado pela variação de preços relativos quando se utilizam dados de valor da produção ou da transformação industrial. A despeito desses problemas, segue sendo o principal indicador utilizado para discutir a questão da heterogeneidade estrutural. A esse respeito ver Kupfer e Rocha (2005) e De Negri e Cavalcante (2014).

4 A opção por esse deflator deveu-se ao acesso amplo e cobertura do período temporal em análise. O Índice de Preços ao Produtor, também calculado pelo IBGE, tem a vantagem de apresentar o deflator separado por atividade econômica. Entretanto, não está disponível para o período em análise, dado que a série histórica inicia em 2009. 
sendo assim, a diferença entre $T$ e 0 a variação temporal de cada variável. $O$ método pode ser expresso pela Equação 2:

$$
\triangle P=\Sigma_{i}\left(P_{i}^{T}-P_{i}^{0}\right) S_{i}^{0}+\Sigma_{i}\left(S_{i}^{T}-S_{i}^{0}\right) P_{i}^{0}+\Sigma_{i}\left(P_{i}^{T}-P_{i}^{0}\right) S_{i}^{0} x\left(S_{i}^{T}-S_{i}^{0}\right)
$$

ou, na forma de taxa de crescimento:

$$
\frac{\Delta P}{P_{n}}=\frac{\Sigma_{i} \Delta S_{i i} P_{i i}}{P_{n}}+\frac{\Sigma_{i} \Delta S_{i i} P_{i i}}{P_{0}}+\frac{\Sigma_{i} \Delta S_{i i} P_{i i}}{P_{0}}
$$

O termo I consiste na componente realocação intrassetorial. O termo II, componente realocação estática, mede se os trabalhadores estão se movendo para atividades com níveis de produtividade acima da média, isto é, mede a capacidade de um determinado porte de empresa e faixa de idade realocar trabalho de atividades com baixa produtividade para outras com níveis mais elevados no período inicial. Já o termo III, realocação dinâmica, representa o efeito conjunto de mudanças nas produtividades setoriais e também na alocação de trabalho entre as atividades. Tal efeito será positivo se as atividades com maiores crescimentos da produtividade também aumentarem sua participação no emprego total, refletindo a capacidade de um determinado porte de empresa e faixa de idade em realocar seus recursos em direção a atividades mais dinâmicas, ou seja, aquelas com maiores taxas de crescimento da produtividade do trabalho.

A interpretação dos termos I - Realocação Intrassetorial, II - Realocação Estática e III - Realocação Dinâmica está resumida no Quadro 1, conforme Torezani (2020), Rocha, Tatsch e Cário (2019) e Timmer, De Vries e De Vries (2014), com base no modelo original de Fabricant (1942).

\section{Quadro 1 - Descrição dos componentes da decomposição da taxa de crescimento da produtividade do trabalho}

\begin{tabular}{|c|c|c|}
\hline Componentes & Causa & Interpretação \\
\hline Realocação Intrassetorial & Mudança de produtividade setorial. & $\begin{array}{c}\text { É positivo quando a produtividade } \\
\text { setorial aumenta. }\end{array}$ \\
\hline Realocação Estática & $\begin{array}{c}\text { Deslocamento do emprego entre setores } \\
\text { de produtividade distinta. }\end{array}$ & $\begin{array}{c}\text { É positivo quando o emprego se desloca } \\
\text { para setores de produtividade maior } \\
\text { que a média. }\end{array}$ \\
\hline Realocação Dinâmica & $\begin{array}{c}\text { Deslocamento do emprego entre setores } \\
\text { com taxas de crescimento da } \\
\text { produtividade distintas. }\end{array}$ & $\begin{array}{c}\text { É positivo quando o emprego se } \\
\text { desloca para setores onde a } \\
\text { produtividade é crescente. }\end{array}$ \\
\hline
\end{tabular}

Fonte: Elaboração própria com base em Rocha, Tatsch e Cário (2019, p. 40). 
Assim, ao estabelecer diferentes componentes, esse método permite identificar distintos fatores que atuam no crescimento produtivo da indústria de transformação.

\section{ANÁLISE DOS RESULTADOS}

A heterogeneidade estrutural, conforme definida originariamente pela CEPAL, se manifesta sempre que houver grandes diferenças na produtividade do trabalho, seja entre os setores da economia, bem como no seu interior. Estas diferenças, quando significativas, são capazes de promover uma segmentação do sistema produtivo e do mercado de trabalho, apresentando estratos de remuneração e condições tecnológicas bastante distintas (PINTO, 1970; SUNKEL, 1978; RODRÍGUEZ, 1998; CEPAL, 2007; 2008; 2010).

O Brasil vivenciou um período de fortes mudanças estruturais nos anos 1990 que, entre outros efeitos, produziu um aumento importante nos níveis de produtividade do trabalho. Entretanto, esse aumento ocorreu em condições que acabaram por reforçar a heterogeneidade estrutural, dado o ambiente macroeconômico hostil com abertura comercial acelerada, câmbio valorizado e juros altos. Esse ambiente causou regressão no comércio exterior e contribuiu para os baixos níveis de investimento e, em especial, do investimento em inovação (KUPFER, 2003).

A difícil situação da indústria brasileira no início dos anos 2000 levou os governos a implementarem planos de política industrial, a saber, a Política Industrial, Tecnológica e de Comércio Exterior (2004), o Plano de Desenvolvimento Produtivo (2008) e o Plano Brasil Maior (2011).

Embora com especificidades e diferenças, o objetivo principal desses planos era a reversão do processo de desindustrialização em curso. Dado o diagnóstico mais geral de forte heterogeneidade produtiva na indústria brasileira, esses planos tinham como focos principais o apoio aos setores de tecnologia de ponta e à inovação no ambiente empresarial, às empresas de menor porte e às atividades exportadoras.

Os resultados dos diversos instrumentos de apoio ao setor empresarial são díspares, embora o diagnóstico mais geral seja de que os planos não conseguiram reverter o processo de desindustrialização. Vale dizer, não se conseguiu avançar na internalização dos mais importantes segmentos da indústria de alta tecnologia, exatamente aqueles que poderiam capitanear o progresso técnico de forma a propiciar a diminuição da heterogeneidade estrutural. Igualmente, o déficit comercial da indústria de transformação brasileira e o processo de especialização regressiva não foram revertidos, embora alguns setores classificados como de alta e média tecnologia foram preservados (NASSIF; FEIJÓ; ARAUJO, 2015; NASSIF; CASTILHO, 2020) 
As principais razões elencadas para as dificuldades enfrentadas na implementação desses planos dizem respeito à fragilidade do aparato institucional da política industrial; às dificuldades impostas pela crise internacional de 2008, especialmente as direcionadas ao financiamento; ao curto prazo de vigência de medidas que almejavam mudanças estruturais mais profundas, entre outros (SUZIGAN; FURTADO, 2010; STEIN; HERRLEIN JÚNIOR, 2016; LAPLANE; LAPLANE, 2017; ULHÔA; BOTELHO; AVELLAR, 2019).

Em um contexto de permanência da heterogeneidade estrutural e de perda de importância da indústria para a economia brasileira, objetiva-se adicionar novos elementos a essa discussão. Investiga-se, para o período de 2007 a 2016, a relação entre produtividade e porte empresarial, segundo uma desagregação por setores de atividade e por idade das empresas no mercado. Como a questão da sobrevivência é crucial para as PMEs, parte-se das hipóteses de que: i) os diferenciais de produtividade entre grandes e pequenas empresas serão menores conforme a longevidade das PMEs aumenta e ii) que há significativas diferenças setoriais segundo o porte e idade das empresas no mercado. ${ }^{5}$

Investiga-se, primeiramente, a evolução da produtividade do trabalho para a indústria de transformação segundo o porte e a idade das empresas em um período de 10 anos, de 2007 a 2016 (Gráficos 1 a 4).

Verifica-se que as MPEs, independente da idade, apresentam baixa produtividade. Há um destaque para as microempresas com mais de 30 anos, no ano de 2008. Este pode ser resultado do período de expansão econômica pelo qual passava o Brasil, acompanhado de políticas públicas voltadas para as MPEs, que envolviam o acesso ao crédito e outros instrumentos de apoio, estabelecidas em planos governamentais, como a Política Industrial, Tecnológica e de Comércio Exterior (PITCE).

Em contrapartida, para as grandes empresas (500 ou mais funcionários), observa-se a produtividade em mais de $\mathrm{R} \$ 135 \mathrm{mil}$ para todos os anos analisados, independente

5 As dificuldades de sobrevivência das empresas de pequeno porte têm sido tratadas na literatura acadêmica desde o trabalho seminal de Steindl (1990). A relação inversa entre porte e sobrevivência postulada pelo autor tem sido verificada, em maior ou menor grau, em todas as economias capitalistas. Para o Brasil, dados sistematizados pelo Serviço Brasileiro de Apoio às Micro e Pequenas Empresas (SEBRAE) comprovam essa relação ao longo do tempo (SEBRAE, 2016). Sobre os determinantes da sobrevivência das pequenas empresas há um enorme conjunto de trabalhos que podem ser divididos em dois grandes grupos: um primeiro relacionado ao capital humano, ou seja, às características pessoais dos empresários (idade, sexo, experiências passadas, senso de oportunidade, independência financeira, entre outros), e um segundo grupo, que tem como objeto as características da empresa e/ou do ambiente em que estão inseridas. A despeito de sua enorme importância, entende-se que o estudo dos determinantes da sobrevivência foge ao escopo do presente trabalho.. 
do tempo de existência. Destaca-se que os dados mostram que a maior taxa de produtividade para as empresas com mais de 30 anos se apresenta para todos os portes de empresas e para todos os anos, sendo quase sempre cerca de duas vezes a produtividade das empresas mais jovens, com menos de 10 anos de existência.

As diferenças de produtividade segundo o porte foram encontradas em trabalhos como o de Kupfer e Rocha (2005), Catela e Porcile (2013b) e Catela, Cimoli e Porcile (2015). Para os autores, o tamanho das firmas é uma variável explicativa para as diferenças de produtividade e, portanto, da heterogeneidade estrutural da indústria brasileira. Para Hidalgo e Mata (2008), as diferenças de produtividade são relacionadas à participação no comércio internacional, na qual os níveis de competição são mais acirrados e mais altas as barreiras à entrada, o que favorece as grandes empresas e reforçam os diferenciais de produtividade. Por sua vez, Lall (1994) relaciona a maior produtividade das grandes empresas aos processos de aprendizado. Como a acumulação do conhecimento se processa das categorias mais simples para as mais complexas, à medida que a empresa cresce e se torna mais madura apresenta melhores condições de know how e capabilities necessárias para uma atuação mais eficiente.

De acordo com os dados dos Gráficos 1 a 4, as empresas de médio porte (100 a 499 trabalhadores) apresentam produtividade na faixa intermediária, entre as de grande e pequeno porte, entretanto, destaca-se que, tanto nesse segmento de empresas, quanto no das micro (0 a 29) e das grandes empresas (mais de 500), não se verifica para todos os anos uma relação direta com a idade, ou seja, encontram-se empresas mais jovens com maior produtividade que as mais longevas. Outro aspecto importante, retratado pelos dados, é a grande diferença de produtividade no segmento das grandes empresas em relação à idade. Em nenhum outro segmento de tamanho, os diferenciais são tão significativos. Entende-se que esses dados evidenciam que a heterogeneidade estrutural é mais ampla e complexa do que se supõe quando se consideram apenas as diferenças de porte.

Analisando a produtividade ao longo do tempo, os dados da Tabela 1 mostram que não houve crescimento de produtividade de 2007 para 2016, embora as empresas com mais de 30 anos de existência tenham apresentado maior produtividade, independente do porte, ao contrário, a produtividade diminuiu. $\mathrm{O}$ valor mais expressivo foi encontrado para as empresas de grande porte com mais de 30 anos, que apresentou queda de $16 \%$ de 2007 para 2016.

Embora se verifique que a produtividade das grandes empresas tenha recuado de 2007 para 2016, houve um crescimento expressivo do VTI, bem como do emprego nesse mesmo período, para as grandes empresas com idade entre 10 e 19 anos e entre 20 e 29 anos. No entanto, para as empresas de grande porte com menos de 10 anos de idade, observa-se que tanto o VTI quanto o emprego diminuíram consideravelmente, sendo 
de $70 \%$ e $74 \%$ respectivamente. Essa diminuição acentuada precisa ser mais profundamente analisada. Uma possível explicação é que são empresas que entraram ou abriram filiais no Brasil no auge do crescimento dos anos 2000 e tiveram suas expectativas de investimento abortadas pela crise que se sucedeu. ${ }^{6}$

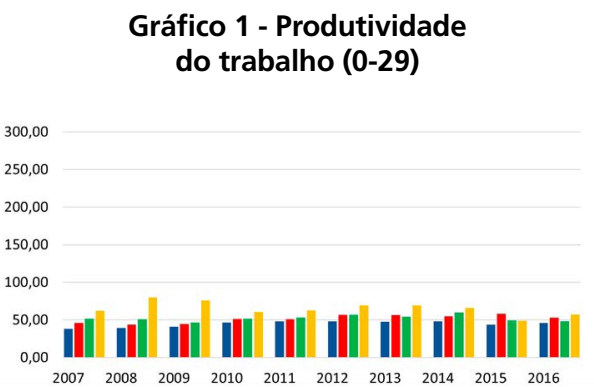

\section{Gráfico 3 - Produtividade do trabalho (100-499)}

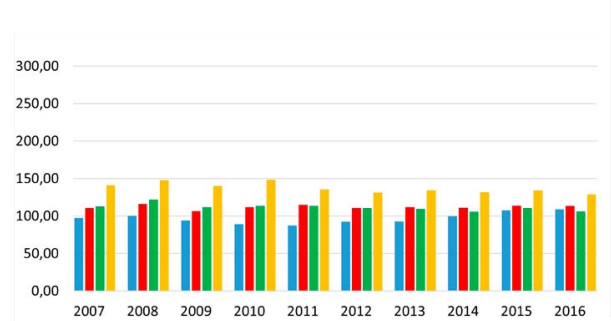

Menos de 10 anos

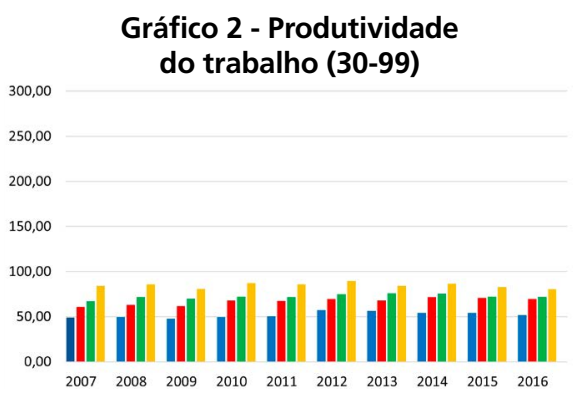

Gráfico 4 - Produtividade do trabalho (500 ou mais)

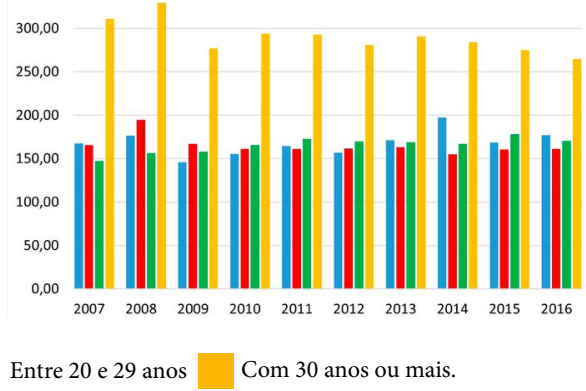

Fonte: Elaboração própria com base em dados de tabulação especial do IBGE (2018).

Registre-se, ainda, que todas as empresas consideradas jovens, até 10 anos, tiveram aumento de produtividade do ano de 2007 para o ano de 2016, porém, pode-se inferir que é resultado da queda do emprego em maior magnitude que a queda do VTI. Esse tanto pode ser indicativo de mudança tecnológica, com maior incorporação de capital, como de aumento da informalidade no mercado de trabalho.

6 Devemos essa observação ao professor Ricardo Bielschowsky, que assistiu a uma apresentação desses dados em um seminário no Centro de Gestão e Estudos Estratégicos (CGEE). 
Tabela 1 - Variação da produtividade, VTI e emprego, segunda faixas de pessoal ocupado, 2007 e 2016

\begin{tabular}{|c|c|c|c|c|}
\hline Pessoal Ocupado & Idade (anos) & $\begin{array}{l}\text { Variação da produtividade } \\
2007-2016\end{array}$ & $\begin{array}{l}\text { Variação do VTI } \\
2007 \text { - } 2016\end{array}$ & $\begin{array}{c}\text { Variação do emprego } \\
2007-2016\end{array}$ \\
\hline \multirow{5}{*}{ Até 29} & Até 10 & $28 \%$ & $-19 \%$ & $-37 \%$ \\
\hline & 10 a 19 & $15 \%$ & $46 \%$ & $27 \%$ \\
\hline & & & & \\
\hline & 20 a 29 & $-9 \%$ & $64 \%$ & $80 \%$ \\
\hline & 30 ou mais & $-8 \%$ & $52 \%$ & $65 \%$ \\
\hline \multirow{4}{*}{ De 30 a 99} & Até 10 & $6 \%$ & $-51 \%$ & $-53 \%$ \\
\hline & 10 a 19 & $12 \%$ & $24 \%$ & $11 \%$ \\
\hline & 20 a 29 & $7 \%$ & $56 \%$ & $45 \%$ \\
\hline & 30 ou mais & $-6 \%$ & $28 \%$ & $35 \%$ \\
\hline \multirow{4}{*}{ De 100 a 499} & Até 10 & $10 \%$ & $-61 \%$ & $-64 \%$ \\
\hline & 10 a 19 & $4 \%$ & $20 \%$ & $16 \%$ \\
\hline & 20 a 29 & $-5 \%$ & $27 \%$ & $34 \%$ \\
\hline & 30 ou mais & $-9 \%$ & $2 \%$ & $12 \%$ \\
\hline \multirow{4}{*}{500 ou mais } & Até 10 & $13 \%$ & $-70 \%$ & $-74 \%$ \\
\hline & 10 a 19 & $-3 \%$ & $57 \%$ & $63 \%$ \\
\hline & 20 a 29 & $15 \%$ & $30 \%$ & $13 \%$ \\
\hline & 30 ou mais & $-16 \%$ & $1 \%$ & $21 \%$ \\
\hline
\end{tabular}

Fonte: Elaboração própria com base em dados de tabulação especial do IBGE (2018).

Outro dado relevante é o que mostra que, em determinadas faixas de porte e idade, o aumento do VTI é menor que o aumento do emprego, sinal de crescimento sem mudança tecnológica. À exceção da faixa de 30 a 99 empregados, nas demais faixas esse fenômeno ocorreu.

A fim de dar mais relevo à relação entre produtividade e longevidade, a Tabela 2 dispõe os dados por idade das empresas e utiliza, como indicador, a produtividade relativa interna. Conforme se nota, são as micro, pequenas e médias empresas na faixa de 10 a 19 anos que mais tiveram ganhos de produtividade em relação às grandes empresas entre 2007 e 2016 . Esses dados não permitem comprovar a hipótese de que há uma relação direta entre produtividade e longevidade, o que é mais um indicador da elevada heterogeneidade da indústria brasileira.

Uma observação que contribui para o entendimento desses dados é a de que houve, entre 2009 e 2012, uma queda importante da taxa de mortalidade das micro e pequenas empresas brasileiras (SEBRAE, 2016). Atribui-se essa queda à situação favorável da 
economia brasileira no período, como o crescimento do PIB e do emprego, queda dos juros, disponibilidade de financiamento, entre outros. Este é um indicativo da importância do ambiente macroeconômico para a competitividade das empresas de pequeno porte.

Tabela 2 - Variação da produtividade relativa interna, segundo faixa de idade das empresas, 2007 e 2016

\begin{tabular}{|c|c|c|c|c|c|}
\hline \multirow{2}{*}{ Idade (anos) } & \multirow{2}{*}{ Pessoal Ocupado } & \multicolumn{2}{|c|}{ Produtividade } & \multicolumn{2}{|c|}{ Produtividade Relativa Interna } \\
\hline & & 2007 & 2016 & 2007 & 2016 \\
\hline \multirow{4}{*}{ Até 10} & 0 a 29 & 37,62 & 48,25 & 0,24 & 0,27 \\
\hline & 30 a 99 & 50,23 & 53,08 & 0,32 & 0,30 \\
\hline & 100 a 499 & 99,70 & 109,31 & 0,63 & 0,61 \\
\hline & 500 ou mais & 157,87 & 177,90 & 1,00 & 1,00 \\
\hline \multirow{4}{*}{10 a 19} & 0 a 29 & 46,88 & 53,95 & 0,29 & 0,34 \\
\hline & 30 a 99 & 62,29 & 69,77 & 0,38 & 0,44 \\
\hline & 100 a 499 & 110,35 & 114,35 & 0,67 & 0,72 \\
\hline & 500 ou mais & 163,53 & 157,80 & 1,00 & 1,00 \\
\hline \multirow{4}{*}{20 a 29} & 0 a 29 & 52,61 & 47,96 & 0,35 & 0,28 \\
\hline & 30 a 99 & 67,00 & 71,87 & 0,45 & 0,42 \\
\hline & 100 a 499 & 112,21 & 106,34 & 0,75 & 0,62 \\
\hline & 500 ou mais & 150,54 & 172,79 & 1,00 & 1,00 \\
\hline \multirow{4}{*}{30 ou mais } & 0 a 29 & 61,90 & 57,08 & 0,20 & 0,21 \\
\hline & 30 a 99 & 84,51 & 79,75 & 0,27 & 0,30 \\
\hline & 100 a 499 & 141,43 & 128,95 & 0,45 & 0,49 \\
\hline & 500 ou mais & 317,04 & 265,48 & $100 \%$ & $100 \%$ \\
\hline
\end{tabular}

Fonte: Elaboração própria com base em dados de tabulação especial do IBGE (2018).

Outra forma de se analisar a heterogeneidade estrutural é por setor. Embora esse seja um aspecto bastante tratado na literatura de referência, neste trabalho foi realizado um esforço para comparar a produtividade por setor por porte e por idade das firmas nos anos de 2007 e 2016. Foram separados os 24 setores de atividade da indústria de transformação, conforme CNAE 2.0. Para elaboração dos gráficos, foram selecionados apenas os setores que apresentaram comportamento diferente do esperado, de acordo com a literatura.

Os setores relacionados no Quadro 2 são, portanto, os que apresentaram comportamento padrão de acordo com o prescrito na literatura, ou seja, à medida em que as empresas desses setores envelhecem, sua produtividade aumenta, independente do porte das empresas. Isso pôde ser observado tanto para 2007 quanto para 2016. 
Quadro 2 - Setores de atividade econômica com comportamento padrão

\begin{tabular}{|c|c|}
\hline Fabricação de produtos de minerais não-metálicos & Fabricação de produtos alimentícios \\
\hline Fabricação de máquinas, aparelhos e materiais elétricos & Fabricação de produtos têxteis \\
\hline Fabricação de outros equipamentos de transporte & Confecção de artigos do vestuário e acessórios \\
\hline Fabricação de móveis & Preparação de couros e fabricação de artefatos \\
\hline Fabricação de produtos diversos & Impressão e reprodução de gravações \\
\hline $\begin{array}{c}\text { Manutenção, reparação e instalação de máquinas } \\
\text { e equipamentos }\end{array}$ & Fabricação de produtos de borracha e de material plástico \\
\hline
\end{tabular}

Fonte: Elaboração própria com base em dados de tabulação especial do IBGE (2018).

No entanto, o mesmo não se pode afirmar sobre os demais setores, os quais apresentaram comportamento da produtividade bastante variado. A fim de identificar o comportamento desses setores, parte-se dos dados agregados setoriais para os anos de 2007 e de 2016 (Gráfico 5). A maior produtividade apresentada é referente ao setor de fabricação de produtos derivados do petróleo e biocombustível, com R 1.216 mil em 2007 e R\$ 1.571 mil em 2016. Exceto para o setor de farmoquímicos, todos os demais apresentaram aumento de produtividade do ano de 2007 para o de 2016.

\section{Gráfico 5 - Produtividade por setor para os anos de 2007 e 2016 (em R\$)

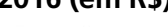

\section{Metalurgia}

Fabricação de produtos químicos

Fabricação de produtos farmoquímicos

Fabricação de produtos do fumo

Fabricação de máquinas e equipamentos

Fabricação de produtos derivados do petróleo e de biocombustíveis

Fabricação de celulose, papel e produtos de papel

Fabricação de bebidas

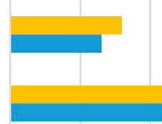


produtividade nesse interim, embora outros apresentem uma produtividade em 2016 menor que a evidenciada em 2007. A maior queda de produtividade foi para as empresas de grande porte observadas em cinco setores da economia (bebidas, produtos químicos, farmoquímicos, metalurgia e outros produtos de transportes), sendo o valor mais expressivo para o setor de metalurgia, com queda de mais de $75 \%$.

\section{Gráfico 6 - Variação da produtividade, por setor, empresas com 0 a 9 anos, 2007/2016}

Outros equipamentos de transporte

Máquinas e equipamentos

Metalurgia

Produtos farmoquímicos e farmacêuticos

$$
\text { Produtos químicos }
$$

Derivados do petróleo e de biocombustíveis

Celulose, papcl c produtos de papel

Produtos do fumo

Bebidas

Indústria de transformação

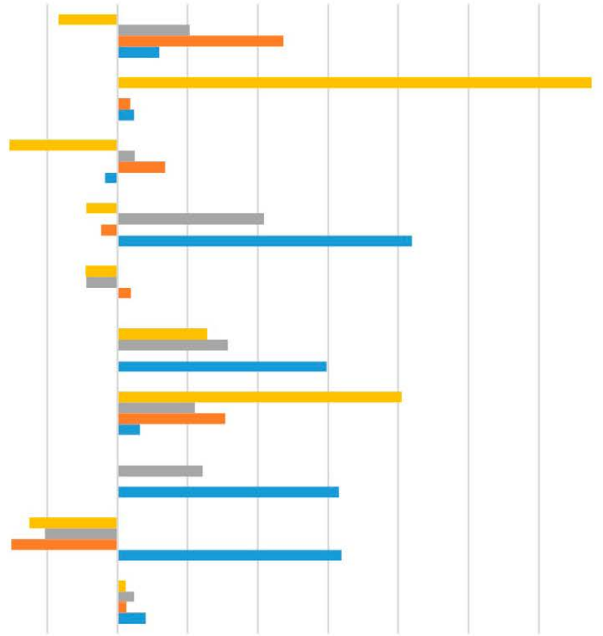

$-100 \%-50 \% \quad 0 \% \quad 50 \% \quad 100 \% \quad 150 \% \quad 200 \% \quad 250 \% \quad 300 \% \quad 350 \%$

Até 29 funcionários Entre 30 e 99 funcionários

Entre 100 e 499 funcionários 500 ou mais

Fonte: Elaboração própria com base em dados de tabulação especial do IBGE (2018).

Vale ressaltar o expressivo aumento de produtividade das MPEs, com destaque para os setores de fabricação de bebidas, mais de 150\% de aumento de 2007 para 2016 (o que parece contraditório, haja vista a queda de produtividade para os demais portes para este setor), de fabricação de produtos de fumo e de derivados do petróleo e biocombustíveis (mais de $150 \%$ ) e fabricação de produtos farmoquímicos, que aumentou mais de $200 \%$ no período.

O Gráfico 7 apresenta os mesmos dados para as empresas com idade entre 10 e 19 anos. O setor de fabricação de derivados de petróleo e biocombustível se destaca em dois sentidos. Para as empresas de grande porte apresenta a maior taxa de crescimento da produtividade nesse período, alcançando crescimento de $899 \%$. No entanto, para as MPEs, observa-se uma queda na produtividade. Em 2007, esse setor, considerando as empresas de pequeno porte (30 a 99 funcionários), apresentou a maior produtividade entre todos os setores da economia, chegando ao patamar de R 715 mil, porém, não 
se mantém ao longo do tempo. Uma das explicações para essa alta produtividade no setor de fabricação de derivados de petróleo e biocombustível foi a descoberta do présal em águas brasileiras.?

Evidencia-se, ainda, que as MPEs desta idade (entre 10 e 19 anos) apresentam aumento de produtividade, mesmo que não seja na mesma proporção das empresas mais jovens. Houve, também, crescimento da produtividade maior para as empresas de pequeno porte ( 0 a 29 empregados) no setor de fabricação de outros equipamentos de transporte e no setor de bebidas e são as duas faixas de menor tamanho (0 a 99 empregados) as maiores responsáveis pelos aumentos de produtividade.

O setor de produtos do fumo, considerando as empresas de pequeno porte (entre 30 e 99 funcionários), também se destacou com aumento de produtividade no patamar de $632 \%$.

\section{Gráfico 7 - Variação da produtividade por setor, empresas com 10 a 19 anos, 2007-2016}

Outros equipamentos de transporte

Máquinas e equipamentos

Metalurgia

Produtos farmoquímicos e farmacêuticos

$$
\text { Produtos químicos }
$$

Derivados do petróleo e de biocombustíveis

Celulose, papel e produtos de papel

Produtos do fumo

Bebidas

Indústria de transformação

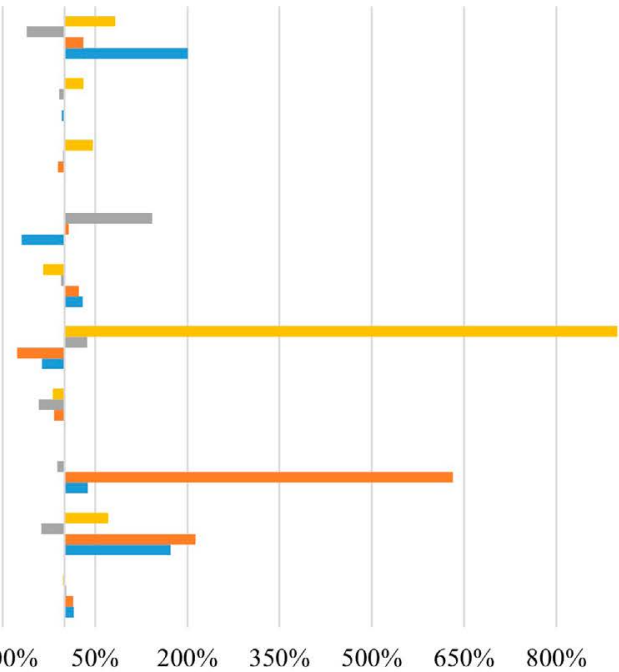

Até 29 funcionários Entre 30 e 99 funcionários

Entre 100 e 499 funcionários 500 ou mais

Fonte: Elaboração própria com base em dados de tabulação especial do IBGE (2018)

7 Segundo a Agência Nacional do Petróleo, Gás Natural e Biocombústivel (ANP), a produtividade dos poços do pré-sal é alta. A produção diária de petróleo no pré-sal passou da média de aproximadamente 41 mil barris por dia, em 2010, para o patamar de 1,35 milhão de barris por dia em junho de 2017. Um crescimento de mais de $3.000 \%$. Nesse mesmo mês, a produção de petróleo no pré sal superou a do pós-sal, que totalizou 1,32 milhão de barris por dia. As mudanças na produção do biocombustível também cooperaram para o resultado da produtividade do setor pois, segundo o Ministério da Agricultura, houve aumento na produção de biocombustível de mais de $200 \%$. 
Para as empresas com idade entre 20 e 29 anos de atuação, o comportamento da taxa de variação da produtividade de 2007 para 2016 é ainda mais distinto que os demais, conforme Gráfico 8.

Deve-se realçar o resultado dos setores de outros equipamentos de transporte, de fabricação de produtos farmoquímicos e de fabricação de bebidas, em que os maiores aumentos de produtividade foram alcançados pelas microempresas ( 0 a 29 trabalhadores).

A avaliação dos resultados dessa faixa de idade ainda permite tecer um comentário acerca dos resultados bastante negativos de três setores direta ou indiretamente ligados à denominada indústria de bens de capital, a saber, fabricação de máquinas e equipamentos, outros equipamentos de transporte e de metalurgia. Nestes setores, as quedas de produtividade foram praticamente generalizadas para todas as faixas de porte das empresas, em especial para o setor de máquinas e equipamentos.

Embora as diferenças setoriais devam ser melhor entendidas em trabalhos específicos, pode-se registrar a avaliação do Instituto Aço Brasil que, em 2017, divulgou uma nota na qual afirmava que uma das razões para a queda de produtividade do setor eram as mudanças na concorrência externa. Segundo o Instituto, um dos fatores significativos daquele momento era o excesso de capacidade global de produção, que ultrapassava 545 milhões de toneladas (280 milhões somente na China).

\section{Gráfico 8 - Variação da produtividade por setor, empresas com 20 a 29 anos, de 2007/2016}

Máquinas e equipamentos

Metalurgia

Produtos farmoquímicos e farmacêuticos

Produtos químicos

Derivados do petróleo e de biocombustíveis

Celulose, papel e produtos de papel

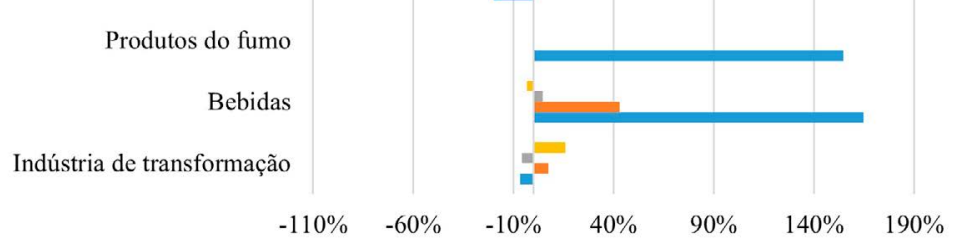

Até 29 funcionários

Entre 30 e 99 funcionários

Entre 100 e 499 funcionários 500 ou mais

Fonte: Elaboração própria com base em dados de tabulação especial do IBGE (2018). 
Outro fator refere-se aos subsídios dados pela China à sua produção, o que também impactou na produtividade do setor no Brasil. De acordo com o Instituto do Aço, a sobretaxa de $25 \%$ para o aço importado de alguns países, incluindo o Brasil, contribuiu de forma negativa na taxa de produtividade do setor. A indústria de máquinas e equipamentos também tem sido fortemente afetada pela concorrência chinesa, conforme mostra o estudo de Almeida (2020).

Por fim, o Gráfico 9 mostra a variação de produtividade de 2007 para 2016 das empresas com mais de 30 anos de atuação.

\section{Gráfico 9 - Variação da produtividade por setor, empresas com 30 anos ou mais, 2007/2016}

Outros equipamentos de transporte

Máquinas e equipamentos

Metalurgia

Produtos farmoquímicos e farmacêuticos

Produtos químicos

Derivados do petróleo e de biocombustíveis

Celulose, papel e produtos de papel

Produtos do fumo

Bebidas

Indústria de transformação
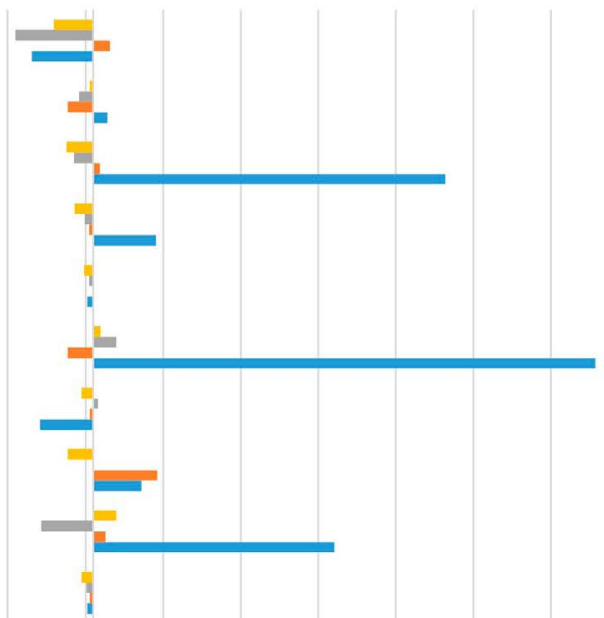

$\begin{array}{lllllllll}-110 \% & -10 \% & 90 \% & 190 \% & 290 \% & 390 \% & 490 \% & 590 \% & 690 \%\end{array}$

Até 29 funcionários

Entre 30 e 99 funcionários

Entre 100 e 499 funcionários $\quad 500$ ou mais

Fonte: Elaboração própria com base em dados de tabulação especial do IBGE (2018).

Verifica-se que foram as empresas que mais apresentaram queda de produtividade no período. Embora os dados apontem as empresas de grande porte do setor de fabricação de derivados de petróleo e biocombustível como as de maior produtividade, sendo de mais de R\$ 1.460 mil em 2007 e R\$ 1.558 mil em 2016, apenas as microempresas do setor apresentaram aumento significativo de produtividade de 2007 para 2016, de 647\%. Destaca-se ainda, o aumento significativo de produtividade para as microempresas dos setores de bebidas (311\%) e metalurgia (454\%).

A distribuição e dispersão dos dados setoriais de produtividade podem ser aferidos recorrendo-se ainda aos gráficos em boxplot apresentados no Apêndice. Os dados foram compilados por setor de atividade econômica, considerando o período 2007-2016, para 
todas as faixas etárias das empresas em conjunto. A diferença entre os gráficos se encontra no porte das empresas contemplado em cada um.

É possível verificar que a variação (amplitude) de produtividade para a maioria dos setores é baixa, sendo que mais de $80 \%$ dos valores das produtividades em seus respectivos setores encontram-se entre o segundo e o terceiro quartil.

Em geral, os setores de bebidas, celulose, químico, farmoquímico, metalurgia, informática, máquinas e materiais elétricos, máquinas e equipamentos e outros equipamentos de transportes apresentam o limite inferior do valor da produtividade acima da média dos demais setores. Isto quer dizer que as empresas destes setores já começam sua produção com produtividade inicial superior aos demais setores.

As maiores amplitudes são relativas aos setores de produção de petróleo e biocombustíveis, produtos farmoquímicos e bebidas, o que demonstra uma grande dispersão da produtividade ao longo do tempo, apresentando vários outliers.

A fim de concluir a análise dos dados da pesquisa, recorreu-se ao método da decomposição estrutural da produtividade. A análise dos três componentes de crescimento do método diferencial-estrutural mostra qual deles teve maior peso (\%) na taxa de crescimento da produtividade do trabalho em cada porte, setor e da empresa.

Verificou-se que a realocação intrassetorial (within-effect) teve maior impacto para as micro e pequenas (de até 10 e de 10 a 19 anos), empresas médias de até 10 anos de existência e as grandes empresas de 20 a 29 anos de existência, as quais obtiveram aumento da produtividade setorial no período analisado (Tabela 3 ).

O segundo componente, o de realocação estática, indica deslocamento do emprego de setores menos produtivos para setores de produtividade maior que a média. Nesse componente, destacam-se as grandes empresas de 10 a 19 anos e as de 30 anos ou mais de existência, assim como as micro, pequenas e médias de 20 a 29 anos de idade. Em menor proporção, aparecem as micro, pequenas e médias de 10 a 19 anos e, em maior proporção, as grandes empresas dessa faixa de idade.

A menor participação percentual no crescimento da produtividade total das empresas em todos os períodos de existência foi atribuída ao componente realocação dinâmica. A transferência de empregos de setores de baixa produtividade para setores de produtividade crescente ocorreu de maneira mais significativa nas grandes empresas de 10 a 19 anos e de 20 a 29 anos de existência. Para as micro e pequenas empresas de 10 a 19 anos o resultado foi positivo, assim como para as pequenas e médias empresas de 20 a 29 anos e as micro e médias de 30 anos ou mais de existência, no entanto, em menor proporção.

Como se pode observar nestes dados, não há preponderância nítida dos efeitos realocação intrassetorial, estática ou dinâmica quando se desagregam os dados por porte e idade. Estes dados complementam os anteriores e indicam uma situação de elevada heterogeneidade. 
Tabela 3 - Decomposição da taxa de crescimento da produtividade do trabalho por porte, setor* e idade, 2007/2016 (em \%)

\begin{tabular}{|c|c|c|c|c|c|}
\hline & & 0 a 29 & 30 a 99 & 100 a 499 & 500 ou mais \\
\hline \multirow{4}{*}{ Realocação intrassetorial } & Até 10 anos & 0,66 & 0,26 & 0,57 & $-0,37$ \\
\hline & 10 a 19 anos & 0,32 & 0,25 & 0,07 & $-0,52$ \\
\hline & 20 a 29 anos & $-0,09$ & 0,07 & $-0,15$ & 0,39 \\
\hline & 30 anos ou mais & $-0,03$ & $-0,04$ & $-0,79$ & $-0,86$ \\
\hline \multirow{4}{*}{ Realocação estática } & Até 10 anos & $-0,27$ & $-0,96$ & $-2,08$ & $-4,61$ \\
\hline & 10 a 19 anos & 0,25 & 0,04 & 0,19 & 1,48 \\
\hline & 20 a 29 anos & 0,75 & 0,40 & 0,52 & $-0,28$ \\
\hline & 30 anos ou mais & 0,18 & 0,30 & 0,24 & 0,93 \\
\hline \multirow{4}{*}{ Realocação dinâmica } & Até 10 anos & $-0,22$ & $-0,15$ & $-0,38$ & $-0,03$ \\
\hline & 10 a 19 anos & 0,07 & 0,03 & 0,00 & 2,52 \\
\hline & 20 a 29 anos & $-0,16$ & 0,05 & 0,11 & 0,71 \\
\hline & 30 anos ou mais & 0,10 & $-0,01$ & 0,14 & $-0,09$ \\
\hline
\end{tabular}

Nota: $\left(^{*}\right)$ O cálculo foi realizado levando em conta os setores da indústria de transformação conforme a análise descritiva. Fonte: Elaboração própria com base em dados de tabulação especial do IBGE (2018).

No geral, as empresas de menor porte e mais jovens foram as que tiveram ganhos de produtividade e para as quais prevaleceu o efeito realocação intrassetorial, o que pode ser um indicativo de que os instrumentos de apoio direcionados a essas empresas no âmbito dos planos de política industrial produziram resultados importantes. De outro lado, para as empresas com mais de 30 anos prepondera uma situação de grandes perdas e realocação do emprego para setores com produtividade acima da média (realocação estática), segundo o cálculo da decomposição da produtividade do trabalho. Foi possível observar que, contrariamente ao postulado pela literatura, parte importante dos setores da indústria brasileira não apresentaram ganhos de know how à medida em que as empresas envelhecem, ganhos esses que poderiam proporcionar aumentos de produtividade. Embora não seja possível aprofundar aqui essa questão, pode-se inferir que a volatilidade do ambiente econômico foi a principal responsável por essa situação. Houve, desde os anos 1980, profundas mudanças nos ambientes interno e externo que foram incapazes de garantir o crescimento sustentado da economia brasileira.

Outro aspecto a ser destacado da análise setorial é a grande mudança de preços relativos ocorrida, em especial, como decorrência do crescimento da China. A grande participação chinesa nas importações brasileiras e nos investimentos diretos tem provocado grandes alterações na estrutura produtiva brasileira, dadas as dificuldades de competição com produtos chineses em vários setores de atividade.

Em suma, os dados analisados neste trabalho indicam que, a despeito de alguns indicadores positivos relacionados às políticas industriais dos anos 2000, estas não foram capazes de alterar a grande heterogeneidade da indústria brasileira. Os diferenciais relativos ao porte, setor e idade não sofreram alterações significativas no período em 
análise, o que reforça e complementa estudos recentes como os de Kupfer e Rocha (2005), Catela (2018) e Torezani (2020).

\section{CONSIDERAÇÕES FINAIS}

O debate sobre a heterogeneidade estrutural da economia brasileira foi ampliado nos últimos anos com as evidências do processo de desindustrialização em curso. Esse debate abarca atualmente várias linhas de pesquisa, especialmente nos campos da economia industrial e do desenvolvimento econômico. Embora o presente trabalho não discuta especificamente esse processo, entende-se que ele contribui para esse debate na medida em que traz novos dados sobre a indústria brasileira, relativos ao período em que ficou patente, segundo vários estudos e metodologias de análise, a perda da importância da indústria para a economia brasileira.

As análises de manifestação de heterogeneidade dependem da metodologia de cálculo utilizada para esse fim. Os indicadores usualmente adotados são: produtividade, comumente usada como a produtividade do trabalho, densidade industrial, market share e estrutura de salários. Para este trabalho, utilizou-se a produtividade do trabalho com o intuito de evidenciar a heterogeneidade estrutural relativa ao porte, setor e idade das empresas na indústria de transformação brasileira de 2007 a 2016. Para isso, foram estabelecidas duas linhas de análise: i) apresentar as diferenças de produtividade ao longo do tempo por porte e por idade; ii) apresentar as diferenças setoriais por porte e por idade em dois pontos do tempo, quais sejam 2007 e 2016. A análise foi complementada pelo uso do método diferencial-estrutural, com a evolução da produtividade decomposta segundo os efeitos de realocação intrassetorial, estática e dinâmica.

Verificou-se que, para a indústria de transformação como um todo, as empresas de grande porte, com mais de 500 funcionários, são as que apresentam as maiores taxas de produtividade, embora também tenham sofrido redução da produtividade de 2007 para 2016.

No que tange às diferenças ao longo do tempo, por porte e por idade das empresas, observou-se que não há uma linha crescente de produtividade. Não foi possível identificar que, à medida que as empresas envelhecem, aumentam a produtividade, como era o resultado esperado. ${ }^{8}$ Ao contrário, observou-se que as empresas maiores (mais de 500

\footnotetext{
8 Em relação a esse aspecto, entende-se serem necessários estudos adicionais que discutam efeitos da idade sobre o crescimento da produtividade. Estudos recentes sobre sobrevivência de empresas mostram que há uma tendência de queda da produtividade à medida que a empresa envelhece, com os resultados mais positivos em termos de performance empresarial concentrados em empresas de 5 a 7 anos (COAD, 2018). Entretanto, dadas as diferentes metodologias desses estudos, comparações mais sistemáticas não são possíveis.
} 
funcionários) e mais antigas (mais de 30 anos de existência) foram as que apresentaram a maior queda de produtividade de 2007 para 2016 e que as empresas jovens e de menor porte sobressaíram-se com as maiores taxas de aumento de produtividade.

Quanto às diferenças setoriais, por porte e por idade, também foi verificada grande heterogeneidade. Não apenas na comparação de um setor com outro, mas dentro do próprio setor, ao se analisar a idade e o tamanho das empresas, identificou-se a existência de significativos diferenciais de produtividade.

O uso do método da decomposição da taxa de crescimento da produtividade mostrou que os componentes realocação estática e realocação dinâmica foram, respectivamente, mais determinantes no percentual do crescimento da produtividade no período analisado, entretanto, a desagregação por porte e por idade das empresas mostrou grandes diferenças sendo mais um indicativo de grande heterogeneidade estrutural.

Entende-se que o conjunto de dados apresentados contribui para o avanço do conhecimento sobre a heterogeneidade estrutural que caracteriza a indústria brasileira e, indiretamente, para a análise do processo de desindustrialização, ao sistematizar a comparação entre os diferentes portes e, em especial, por agregar informações de idade das empresas, variável que não foi analisada em nenhum dos trabalhos sobre o tema, até onde é de conhecimento das autoras.

Os resultados encontrados permitem mostrar, em suma, que não há uma separação simples entre pequenas empresas de baixa produtividade e grandes empresas de alta produtividade. Tampouco é possível atribuir às empresas mais longevas as mais altas taxas de produtividade, dado que se encontraram significativas diferenças intersetoriais quando cruzados os dados de idade e setor de atividade.

Esses achados corroboram e agregam novas informações a outros estudos recentes que comprovaram a existência de heterogeneidade estrutural no setor industrial brasileiro. Em termos de desenvolvimento futuro dessa linha de investigação, uma análise mais detalhada, observando os microdados para as empresas, poderá contribuir de forma mais precisa para identificar a manifestação de heterogeneidade e, principalmente, apontar os seus determinantes, em nível micro ou macroeconômico. A ampliação do tempo de análise e o uso de métodos econométricos é outra possível linha de investigação futura.

\section{REFERÊNCIAS}

ALMEIDA, K. P. Caracterização e evolução da inovação tecnológica e do apoio das políticas públicas na indústria brasileira de máquinas e equipamentos: uma análise a partir da Pesquisa de Inovação (PINTEC). Dissertação (Mestrado em Economia) - Universidade Federal de Uberlândia, Uberlândia, 2020. 
ARAÚJO, E. S.; COSTA, K. G. V. Heterogeneidade estrutural, precarização das condições de trabalho e pleno emprego no ciclo de desenvolvimento da economia brasileira entre 20022011. Revista Economia \& Tecnologia, v. 8, n. 3, p. 5-18, 2012.

BRESSER-PEREIRA, L. C. The Dutch disease and its neutralization: a Ricardian approach. Revista de Economia Política, v. 28, n. 1, p. 47-71. 2008.

CANO, W. A desindustrialização do Brasil. Economia e Sociedade, v. 21, n. especial, p. 831-851, 2012.

CATELA, E. Y.; CIMOLI, M.; PORCILE, G. Productivity and structural heterogeneity in the Brazilian manufacturing sector: Trends and determinants. Oxford Development Studies, v. 43, n. 2, p. 232-252, 2015.

CATELA, E. Y.; PORCILE, G. Heterogeneidade estrutural na produtividade das firmas brasileiras. Brasília, DF: CEPAL/IPEA, 2013a.

CATELA, E. Y.; PORCILE, G. Produtividade setorial da indústria brasileira: uma análise dos determinantes a partir de regressão quantílica para painel de dados com efeitos fixos. In: ENCONTRO NACIONAL DE ECONOMIA, 46., 2013, Foz do Iguaçu. Anais [...]. Niterói: ANPEC, 2013b.

CATELA, E. Y. Las micro, pequeñas y medias empresas brasileñas en el período reciente: pérdida de profundidad productiva y exportadora en un período de dinamismo de política industrial. In: DINI, M.; STUMPO, G. (Coords.). Mipymes en América Latina: Un frágil desempeño y nuevos desafíos para las políticas de fomento. Santiago: CEPAL, 2018.

CEFIS, E.; MARSILI, O. Survivor: The role of innovation in firms' survival. Research Policy, v. 35 n. 5, p. 626-641, 2006.

CEPAL - COMISSÃO ECONÔMICA PARA A AMÉRICA LATINA E O CARIBE. Progreso técnico y cambio estructural en América Latina. Santiago: CEPAL, 2007.

CEPAL - COMISSÃO ECONÔMICA PARA A AMÉRICA LATINA E O CARIBE. La transformación productiva 20 años después: Viejos problemas, nuevas oportunidades. Santiago: CEPAL, 2008.

CEPAL - COMISSÃO ECONÔMICA PARA A AMÉRICA LATINA E O CARIBE. La hora de la igualdad: Brechas por cerrar, caminos por abrir. Santiago: Naciones Unidas, 2010.

CIMOLI, M. Heterogeneidad estructural, asimetrías tecnológicas y crecimiento en América Latina. Santiago: CEPAL - COMISSÃO ECONÔMICA PARA A AMÉRICA LATINA E O CARIBE, 2005.

COAD, A. Firm age: A survey. Journal of Evolutionary Economics, v. 28, p. 13-43, 2018.

COAD, A. et al. Firm age and performance. Journal of Evolutionary Economics, v. 28, p. 1-11, 2018.

CORREA, F.; LEIVA, V.; STUMPO, G. Mipymes y heterogeneidad estructural en América Latina. In: DINI, M.; STUMPO, G. (Coords.). Mipymes en América Latina: Un frágil desempeño y nuevos desafios para las políticas de fomento. Santiago: CEPAL, 2018.

DE NEGRI, F.; CAVALCANTE, L. R. Os dilemas e os desafios da produtividade no Brasil. In: DE NEGRI, F; CAVALCANTE, L. R. (Orgs.) Produtividade no Brasil: desempenho e determinantes. Brasília, DF: ABDI/IPEA. 2014.

DOSI, G.; LECHEVALIER, S.; SECCHI, A. Introduction: Interfirm heterogeneity -nature, sources and consequences for industrial dynamics. Industrial and Corporate Change, v. 19, n. 6, p. 1867-1890, 2010. 
DOSI, G.; NELSON, R. R. Technological advance as an evolutionary process. In: NELSON, R. R. et al. Modern evolutionary economics. Cambridge: Cambridge University Press, 2018. p. 35-84.

FABRICANT, S. Employment in Manufacturing, 1899-1939. New York: NBER, 1942.

FURTADO, C. Teoria e política do desenvolvimento econômico. 2. ed. São Paulo: Nova Cultural, 1986.

GRAZZI, M; MOSCHELLA, D. Small, young and exporters: New evidence on the determinants of firm growth. Journal of Evolutionary Economics, v. 28, p. 125-152, 2018.

GUSSO, D. A.; NOGUEIRA, M. O.; VASCONCELOS, L. F. Heterogeneidade Estrutural: Uma retomada conceitual. Brasília, DF: Ipea, 2011.

HIDALGO, A. B.; MATA, D. Produtividade e desempenho exportador das firmas na indústria de transformação brasileira. In: ENCONTRO NACIONAL DE ECONOMIA, 36., 2008, Salvador. Anais [...]. Niterói: ANPEC, 2008.

IBGE - INSTITUTO BRASILEIRO DE GEOGRAFIA E ESTATÍSTICA. Pesquisa Industrial Anual - Empresa. [On-line] IBGE, 2019a. Disponível em: https://bit.ly/2RQYWU0. Acesso em: 29 jan. 2019.

IBGE - INSTITUTO BRASILEIRO DE GEOGRAFIA E ESTATÍSTICA. Estatísticas do Cadastro Central de Empresas: o que é. [Online] IBGE, 2019b. Disponível em: https://bit.ly/3uuICWy. Acesso em: 29 jan. 2019.

IBGE - INSTITUTO BRASILEIRO DE GEOGRAFIA E ESTATÍSTICA. Base de dados da Pesquisa Industrial Anual - Empresa (PIA-Empresa) dos anos de 1996 a 2016 e do Cadastro Central de Empresas (CEMPRE) dos anos de 1996 a 2016. Rio de Janeiro: IBGE, 2018. [Solicitação por meio de correio eletrônico ao IBGE. Arquivos recebidos por botelhomr@ufu.br em 19 de out. de 2018.]

INFANTE, R. El desarrollo inclusivo en América Latina y el Caribe: Ensayos sobre políticas de convergencia productiva para la igualdad. Santiago: Naciones Unidas, 2011.

KUPFER, D. Política Industrial: Dossiê Política Industrial. Revista Econômica, v. 5, n. 2, p. 281-98, 2003.

KUPFER, D.; ROCHA, F. Productividad y heterogeneidad estructural en la industria brasileña. In: CIMOLI, M. (Ed.). Heterogeneidad estructural, asimetrías tecnológicas y crecimiento en América Latina. Santiago: CEPAL, 2005.

LALL, S. Technological capabilities and industrialization. World Development, v. 20, n. 2, p. 165$86,1994$.

LAPLANE, M.; LAPLANE, A. Planes industriales y los desafíos del desarrollo sostenible en Brasil. In: CEPAL - COMISSÃO ECONÔMICA PARA A AMÉRICA LATINA E O CARIBE. Políticas industriales y tecnológicas en América Latina, 2017. Santiago: CEPAL, 2017. p. 133-174.

LEWIS, W. A. Economic development with unlimited supplies of labour. The Manchester School, v. 22, n. 2, p. 139-191, 1954.

MATOS, M.; ARROIO, A. Políticas de apoio a micro e pequenas empresas no Brasil: Avanços no período recente e perspectivas futuras. Santiago: Nações Unidas, 2011.

NASSIF, A.; CASTILHO, M. Trade patterns in a globalised world: Brazil as a case of regressive specialization. Cambridge Journal of Economics, v. 44, p. 671-701, 2020. 
NASSIF, A.; FEIJÓ, C.; ARAUJO, E. Structural change and economic development: is Brazil catching up or falling behind? Cambridge Journal of Economics, v. 39, n. 5, p. 1307-1332, 2015.

NELSON, R. R. Why do firms differ, and how does it matter? Strategic Management Journal, v. 12, n. especial, p. 61-74, 1991.

NELSON, R. R.; WINTER, S. G. In search of a useful theory of economic change. Cambridge: Harvard University Press, 1982.

NOGUEIRA, M. O. Um pirilampo no porão: Um pouco de luz nos dilemas da produtividade das pequenas empresas e da informalidade no Brasil. Brasília, DF: Ipea, 2017.

OECD - ORGANISATION FOR ECONOMIC CO-OPERATION AND DEVELOPMENT. The SME financing gap. Paris: OECD, 2006.

PALMA, G. Cuatro fuentes de "desindustrialización" y un nuevo concepto de "síndrome holandés". In: OCAMPO, J. A. (Ed.) Más allá de las reformas: Dinámica estructural y vulnerabilidad macroeconómica. Bogotá: CEPAL/Alfaomega, 2005.

PAVITT, K. Sectoral patterns of technological change: towards a taxonomy and a theory. Research Policy, v. 13, n. 6, p. 343-75, 1984.

PINTO, A. Naturaleza e implicaciones de la "heterogeneidad estructural" de la América Latina. El trimestre económico, v. 37, n. 145, p. 83-100, 1970.

PREBISCH, R. Crecimiento, desequilibrio y disparidades: Interpretación del proceso de desarrollo económico. In: Estudio económico de América Latina. Santiago: CEPAL, 1950. p. 3-89.

ROCHA, C. C.; TATSCH, A. L.; CÁRIO, S. A. F. Mudança estrutural e seu impacto na produtividade: Uma análise da ascensão do setor de serviços na economia brasileira. Revista Economia Ensaios, v. 33, n. especial, p. 26-45, 2019.

RODRÍGUEZ, O. Heterogeneidad estructural y empleo. Revista de la Cepal, n. especial, p. 315-321, 1998.

SEBRAE - SERVIÇO BRASILEIRO DE APOIO ÀS MICRO E PEQUENAS EMPRESAS. Anuário do trabalho na micro e pequena empresa: 2010-2011. 5. ed. Brasília, DF: SEBRAE, 2012.

SEBRAE - SERVIÇO BRASILEIRO DE APOIO ÀS MICRO E PEQUENAS EMPRESAS. Sobrevivência das empresas no Brasil. Brasília, DF: SEBRAE, 2016.

SOLOW, R. M. A contribution to the theory of economic growth. The Quarterly Journal of Economics, v. 70, n. 1, p. 65-94, 1956.

SOUZA, M. C. A. F.; MAZZALI, L. Conceito e espaço da pequena empresa na estrutura industrial: heterogeneidade e formas de inserção. Revista Gestão \& Produção, v. 15, n. 3, p. 591-603, 2008.

SQUEFF, G. C.; NOGUEIRA, M. O. A heterogeneidade estrutural no Brasil de 1950 a 2009. In: INFANTE, R.; MUSSI, C.; NOGUEIRA, M. O. (Ed.). Por um desenvolvimento inclusivo: O caso do Brasil. Santiago: CEPAL; Brasília, DF: OIT/Ipea, 2015.

STEIN, G. Q.; HERRLEIN JÚNIOR, R. Política Industrial no Brasil: uma análise das estratégias propostas na experiência recente (2003-2014). Planejamento e Políticas Públicas, n. 47, p. 251-287, 2016.

STEINDL, J. Pequeno e grande capital: Problemas econômicos do tamanho das empresas. São Paulo: Editora Hucitec, 1990. 
SUNKEL, O. La dependencia y la heterogeneidad estructural. Trimestre Económico, v. 45, n. 1, p. 3-20, 1978.

SUZIGAN, W.; FURTADO, J. Instituições e políticas industriais e tecnológicas: Reflexões a partir da experiência brasileira. Revista Estudos Econômicos, v. 40, n. 1, p. 7-41, 2010.

TEECE, D.; PISANO, G. The dynamic capabilities of firms: An introduction. Industrial and Corporate Change. v. 3, n. 3, p. 537-556, 1994.

TIMMER, M. P.; DE VRIES, G.; DE VRIES; K. Patterns of Structural Change in Developing Countries. Groningen: Groningen Growth and Development Centre, 2014.

TOREZANI, T. A. Produtividade da indústria brasileira: decomposição do crescimento e padrões de concentração em uma abordagem desagregada, 1996-2016. Revista Brasileira de Inovação, v. 19, e0200029, 2020.

ULHÔA, W.; BOTELHO, M. R. A.; AVELLAR, A. P. M. Política industrial no Brasil nos anos 2000: Uma análise sob a perspectiva da execução orçamentária da União. Planejamento e Políticas Públicas, n. 53, p. 81-114, 2019. 


\section{APÊNDICE}

Os Gráficos de 1 a 4 foram construídos a partir dos dados de tabulação especial do IBGE (2018). O Quadro 1 se refere à legenda dos gráficos, representando os setores da economia, segundo a classificação CNAE 2.0.

\section{Quadro 1 - Legenda dos gráficos de 1 a 4}

\begin{tabular}{|c|c|c|c|}
\hline 1. Produtos alimentícios & 2. Fabricação de bebidas & 3. Produtos do fumo & 4. Produtos têxteis \\
\hline 5. Vestuário e acessórios & 6. Artefatos de couro & 7. Produtos de madeira & 8. Celulose e papel \\
\hline 9. Impressão e gravações & $\begin{array}{c}\text { 10. Petróleo, } \\
\text { biocombustível }\end{array}$ & 11. Produtos químicos & 12. Farmoquímicos \\
\hline 13. Borracha e plástico & 14. Minerais não-metálicos & 15. Metalurgia & 16. Produtos de metal \\
\hline $\begin{array}{c}\text { 17. Informática, eletrônicos } \\
\text { e ópticos }\end{array}$ & $\begin{array}{c}\text { 18. Máquinas e materiais } \\
\text { elétricos }\end{array}$ & $\begin{array}{c}\text { 19. Máquinas e } \\
\text { equipamentos }\end{array}$ & 20. Veículos automotores \\
\hline $\begin{array}{c}\text { 21. Outros equipamentos } \\
\text { de transporte }\end{array}$ & 22. Fabricação de móveis & $\begin{array}{c}\text { 23. Fabricação de produtos } \\
\text { diversos }\end{array}$ & $\begin{array}{c}\text { 24. Manutenção e } \\
\text { instalaço de máquinas e } \\
\text { equipamentos }\end{array}$ \\
\hline
\end{tabular}

\section{Gráfico 1 - Produtividade por setor, para empresas com até 29 funcionários}

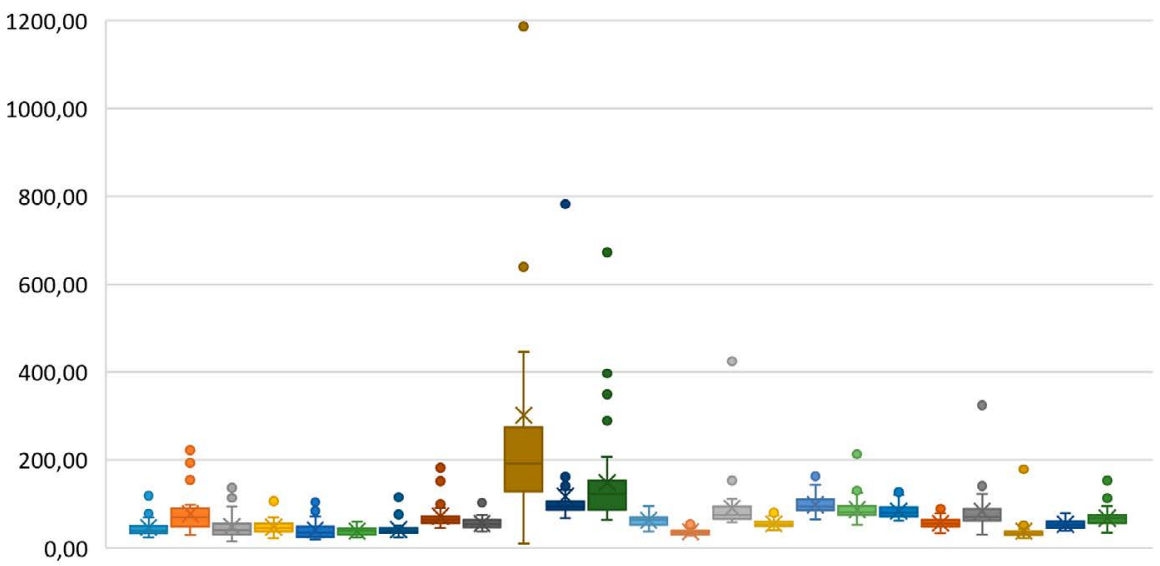




\section{Gráfico 2 - Produtividade por setor, para empresas com 30 a 99 funcionários}

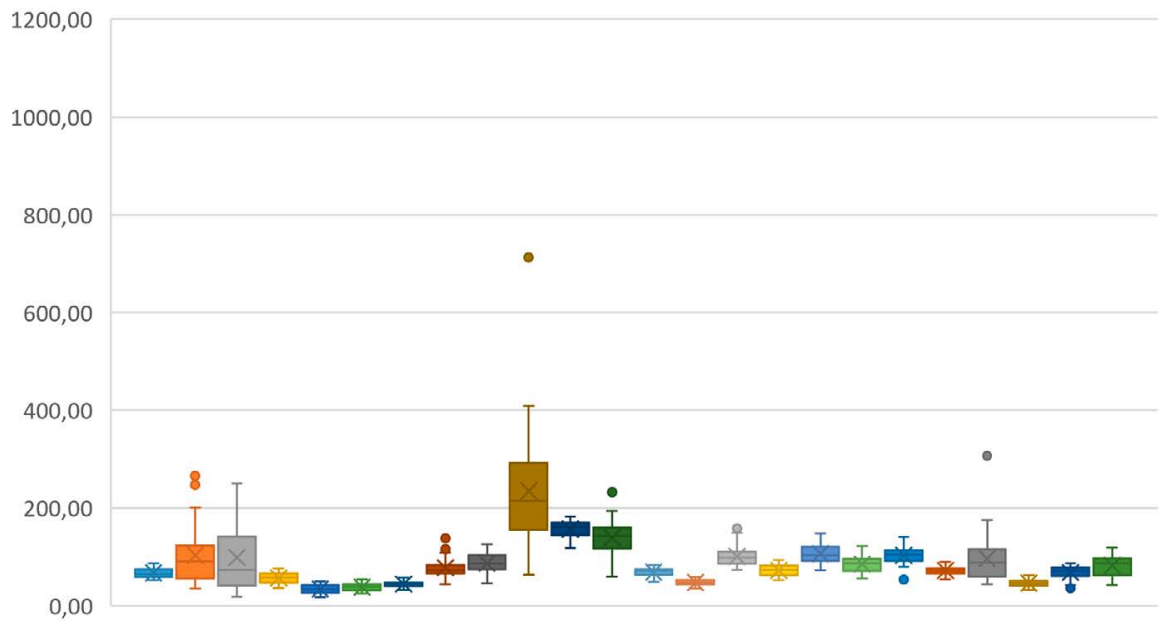

Gráfico 3 - Produtividade por setor, para empresas com 100 a 499

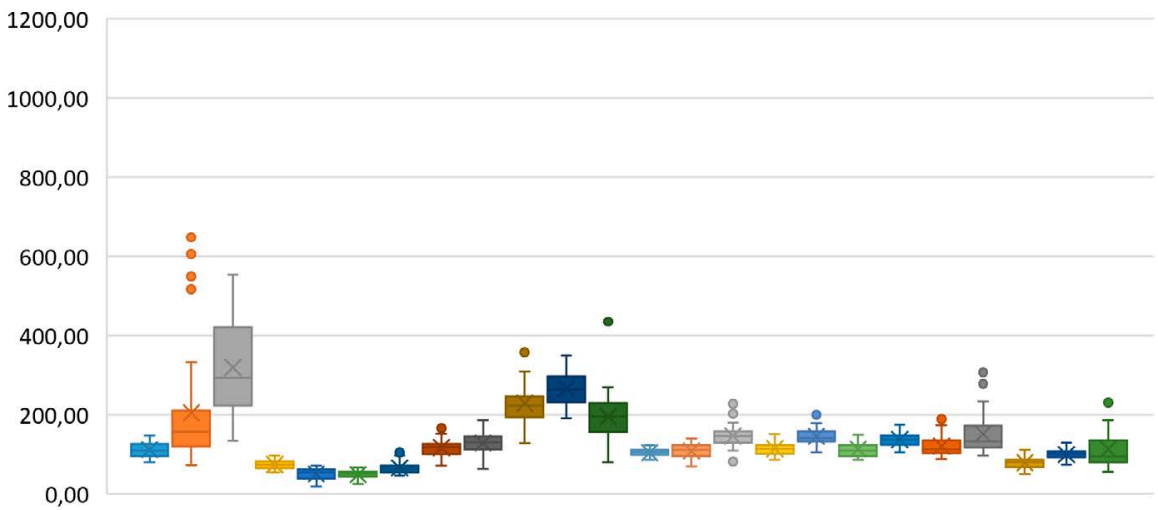




\section{Gráfico 4 - Produtividade por setor, para empresas com 500 ou mais funcionários}

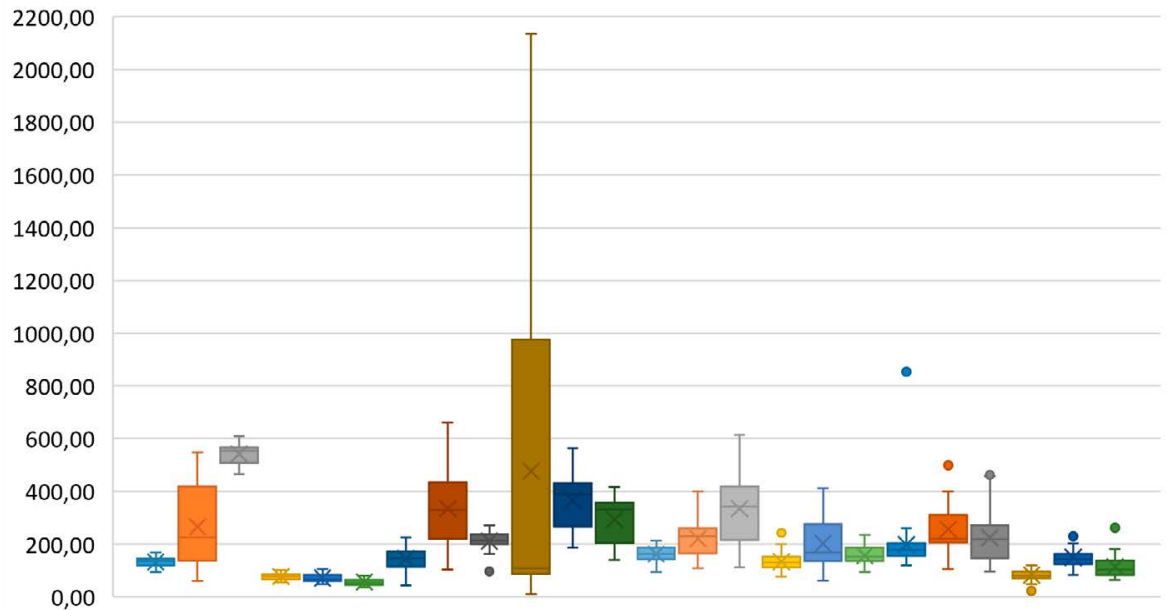

Fonte: Elaboração própria com base em tabulação especial do IBGE (2018). 